\title{
Correction to: Development of integrated deep learning and machine learning algorithm for the assessment of landslide hazard potential
}

\author{
Bilal Aslam ${ }^{1}\left(\mathbb{D} \cdot\right.$ Adeel Zafar $^{1} \cdot$ Umer Khalii $^{2}$
}

Published online: 15 September 2021

(C) Springer-Verlag GmbH Germany, part of Springer Nature 2021

\section{Correction to: Soft Computing}

https://doi.org/10.1007/s00500-021-06105-5

Name of the third author was published incorrect as Umar Khalil

The correct name is Umer Khalil

The original article has been updated.

Publisher's Note Springer Nature remains neutral with regard to jurisdictional claims in published maps and institutional affiliations.

The original article can be found online at https:// doi.org/10.1007/s00500-021-06105-5.

\section{Bilal Aslam}

bilalaslam45@gmail.com

1 Department of Cyber Security and Data Science, Riphah International University, Islamabad Campus, Islamabad, Pakistan

2 Department of Civil Engineering, COMSATS University Islamabad, Wah Campus, Wah Cantt, Pakistan 